\title{
A Case of Lung Cancer Originating from Cavitary Mycobacterium xenopi Infection
}

\author{
Viral K Doshi MD, Shreedhar R Kulkarni MD, Nang M Kham MD, \\ and Kent S Kapitan MD
}

\begin{abstract}
Coexistence of Mycobacterium xenopi with lung cancer has been reported. However, lung cancer originating within a pre-existing cavity caused by M. xenopi has not. A 55-y-old woman with a history of smoking presented with complaints of chronic dry cough, night sweats, and weight loss for several months. Computed tomography (CT) scanning revealed a $3.5-\mathrm{cm}$ irregular thick-walled cavity in the right lung apex. Cultures obtained from a CT-guided biopsy grew M. xenopi. The patient received standard treatment, and her clinical symptoms improved, and the radiographic lesion stabilized. However, 2 y later, a repeat chest $x$-ray showed the original right upper lobe cavity with an interval development of a mass adjoining the cavity. A CT-guided needle biopsy of the new mass demonstrated squamous cell carcinoma. Whenever there is a change in the radiological appearance of a cavity, a repeat biopsy should be performed to exclude lung cancer. Key words: lung neoplasm; squamous cell carcinoma; scar cancer; M. xenopi; cavitary lung lesions. [Respir Care 2015;60(3):e56-e58. (C) 2015 Daedalus Enterprises]
\end{abstract}

\section{Introduction}

Cavitary lung lesions are radiologically defined as aircontaining lesions with a wall within an area of a surrounding density, mass, or nodule. ${ }^{1}$ Cavitary Mycobacterium xenopi infection is more commonly reported in Canada, the United Kingdom, and Europe. ${ }^{2}$ Cavitation is present in up to $20 \%$ of lung cancers and typically occurs in squamous cell carcinoma. ${ }^{1}$ Coexistence of M. xenopi with lung cancer has been reported. ${ }^{3}$ However, to our knowledge, lung cancer originating within a pre-existing cavity caused by $M$. xenopi has not been reported.

\footnotetext{
Drs Doshi and Kapitan are affiliated with the Division of Pulmonary and Critical Care Medicine, and Dr Kulkarni and Kham are affiliated with the Department of Internal Medicine, Southern Illinois University School of Medicine, Springfield, Illinois.
}

The authors have disclosed no conflicts of interest.

Correspondence: Viral K Doshi MD, Division of Pulmonary and Critical Care Medicine, Southern Illinois University School of Medicine, PO Box 19636, Springfield, IL 62794-9636. E-mail: viralkdoshi@gmail.com.

DOI: $10.4187 /$ respcare. 03549

\section{Case Report}

A 55-y-old homeless woman with schizoaffective disorder and a 30 pack-year history of cigarette smoking was admitted to the hospital for treatment of psychosis with complaints of a cough of several months duration. She was a poor historian and had not seen a physician in decades. She also complained of intermittent shortness of breath, unintentional weight loss, and occasional night sweats over the past few months. Physical examination was unremarkable. Chest x-ray (Fig. 1) and computed tomography (CT) scan (Fig. 2) revealed a 3.5-cm irregular thick-walled cavity in the right apex with a thickness of $\sim 6 \mathrm{~mm}$. Three sputum smears were acid-fast bacilli-negative, and Lowenstein cultures were also negative. Fungal serologies, including Blastomyces, Coccidioides, and Histoplasma, were negative. Human immunodeficiency virus and interferon gamma releasing assay for tuberculosis were also negative. Bronchoscopy with bronchoalveolar lavage was unrevealing. A CT-guided fine needle aspiration biopsy demonstrated necrotizing granulomatous inflammation with acid-fast bacilli. The culture was positive, and M. xenopi was identified by polymerase chain reaction. The patient received treatment with rifampin, ethambutol, and clarithromycin for 18 months. Her symptoms resolved. The cavity slightly regressed radiologically and then remained 


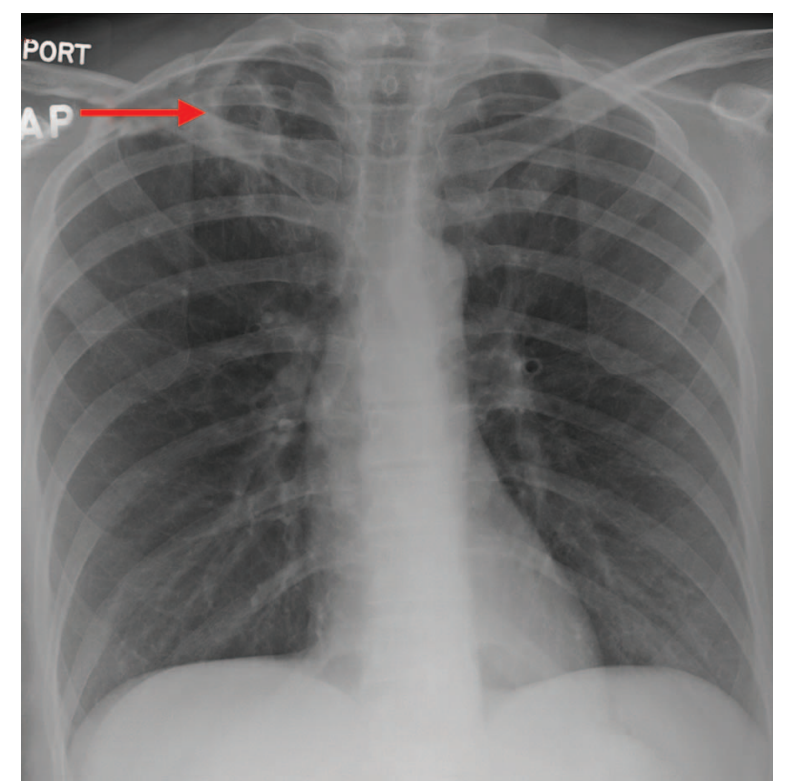

Fig. 1. Initial chest x-ray showing right upper lobe cavitary lesion (arrow).

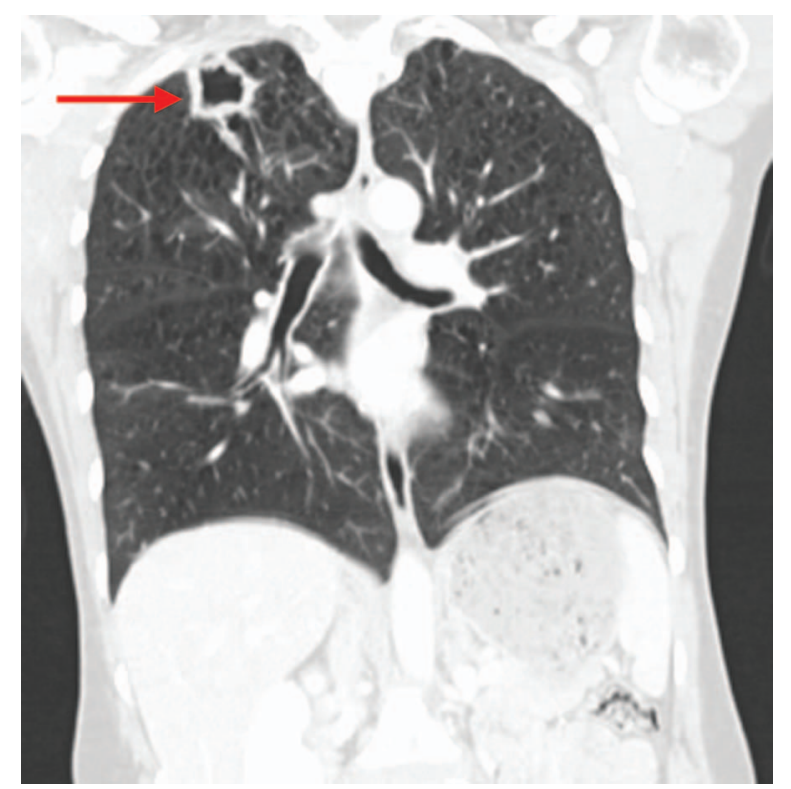

Fig. 2. Initial coronal computed tomography scan showing right upper lobe cavitary lesion (arrow).

unchanged for 18 months. Repeat cultures at 6,12 , and 18 months were negative.

Two y after the initial diagnosis, a routine chest $\mathrm{x}$-ray (Fig. 3) revealed the original cavity with a new enlarging density on its inferolateral wall. A follow-up CT scan (Fig. 4) revealed an enlarged right upper lung cavity with the interval development of a spiculated irregular density inferolateral to the cavity accompanied by right hilar lymphadenopathy. A CT-guided lung biopsy of the mass re-

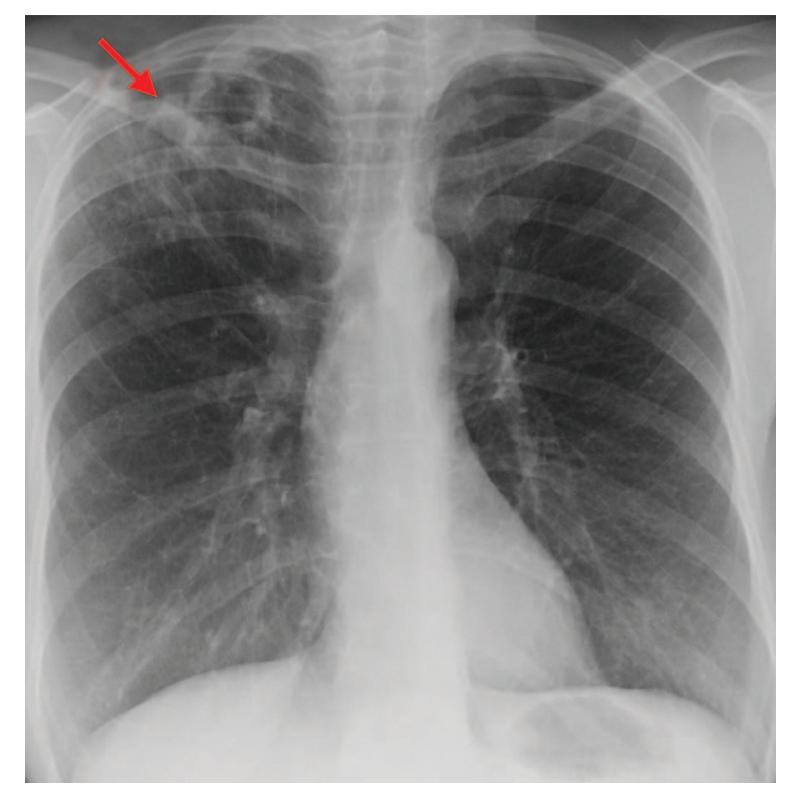

Fig. 3. Chest $x$-ray after 2 y showing irregular density inferior to the cavitary lesion (arrow).

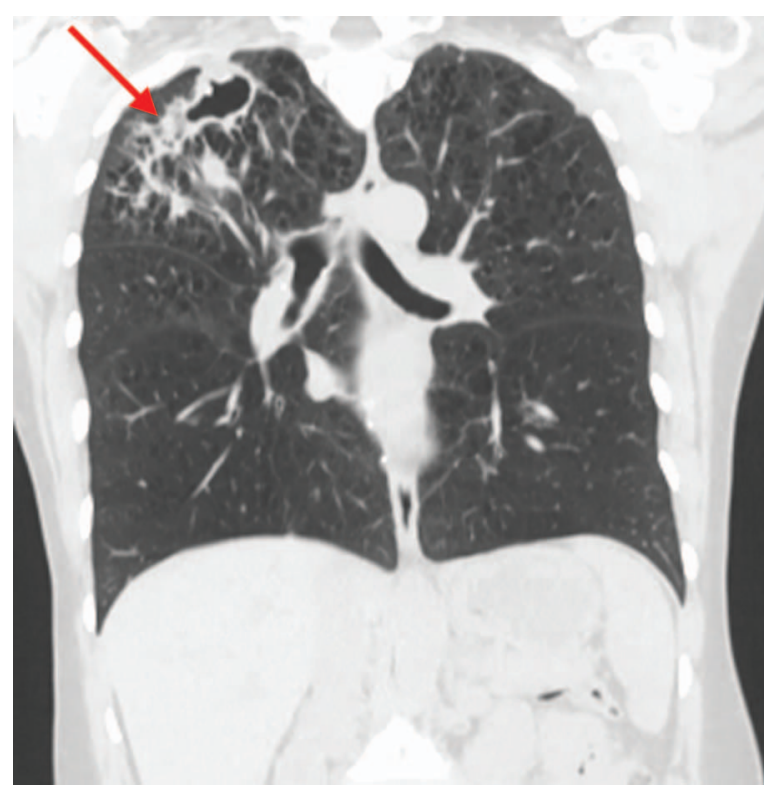

Fig. 4. Coronal computed tomography scan after 2 y showing inferolateral spiculated irregular density originating from the cavity (arrow).

vealed poorly differentiated squamous cell carcinoma. The patient underwent a right upper lobectomy, which confirmed an invasive poorly differentiated squamous cell carcinoma with pleural invasion, as well as a few acid-fast bacilli and an aspergilloma within the center of the cavity. Positron emission tomography was negative for mediastinal lymph nodes and distant metastasis. The patient was pathologically diagnosed with stage $2 \mathrm{~B}$ lung cancer. How- 
ever, she declined adjuvant chemotherapy and was lost to follow-up.

\section{Discussion}

M. xenopi pulmonary infection is associated with immune suppression and underlying lung diseases such as COPD, as in this case. ${ }^{2}$ Multiple cases of coexisting infection and malignancy have been reported. ${ }^{1}$ Both tuberculous $^{4}$ and atypical (especially Mycobacterium avium complex $)^{5}$ mycobacteria have been associated lung cancer. There have been only 2 cases reported of $M$. xenopi being associated with lung cancer: one with adenocarcinoma and one with large cell carcinoma., 3 To our knowledge, this is the first reported case of squamous cell carcinoma originating from a treated cavitary M. xenopi infection. Aspergilloma is a saprophytic infection that occurs as a colonizer of pre-existing cavity lesions, as in this case. ${ }^{3}$

Our patient had a cavitary M. xenopi infection that was adequately treated and radiographically stable for 18 months. A mass developed thereafter, and a repeat CT-guided needle biopsy showed evidence of malignancy. Cavitary lesions are common in patients with squamous cell carcinoma. ${ }^{3}$ Cigarette smoking certainly contributed to her risk of subsequent squamous cell carcinoma, ${ }^{6}$ but it is unlikely that she had pre-existing cancer at the time of her initial presentation, as her initial biopsy did not show any evidence of malignancy, and it is unlikely that a poorly differentiated squamous cell carcinoma would remain radiographically inapparent for 18 months. Of the non-small cell lung cancer subtypes, several studies have shown squamous cell carcinoma to be one of the more rapidly growing tumor subtypes. ${ }^{7,8}$

Woodring et $\mathrm{al}^{9,10}$ found the thickest section of a cavity wall to be the most useful factor in differentiating a malignant from a nonmalignant etiology of cavity and found that most cavities ( $>90 \%$ cases) with a wall thickness of $>15 \mathrm{~mm}$ were malignant. Although chronic inflammation and scarring caused by the infection can lead to cancer, malignant tumors in turn can lead to immunosuppression and thereby promote opportunistic infections. ${ }^{11}$ Chronic inflammation leading to scar carcinoma has been reported, and such findings have been seen in infections with $M y$ - cobacterium tuberculosis ${ }^{4}$ and the M. avium complex ${ }^{5,12}$ and therefore seem possible for M. xenopi, as in our case.

Lung cancer can arise from cavities left behind by infections such as M. xenopi. Smoking and chronic inflammation leading to scarring may also result in cancer. These findings suggest that residual cavities should be closely monitored. Whenever there is a change in the radiographic appearance of a cavity, the possibility of a new lung cancer should be considered and confirmed by biopsy, even though a previous biopsy demonstrated only an infectious etiology of the cavity.

\section{REFERENCES}

1. Gadkowski LB, Stout JE. Cavitary pulmonary disease. Clin Microbiol Rev 2008;21(2):305-333.

2. Griffith DE, Aksamit T, Brown-Elliott BA, Catanzaro A, Daley C, Gordin F, et al. An official ATS/IDSA statement: diagnosis, treatment, and prevention of nontuberculous mycobacterial diseases. Am J Respir Crit Care Med 2007;175(4):367-416.

3. Souilamas R, Danel C, Chauffour X, Riquet M. Lung cancer occurring with Mycobacterium xenopi and Aspergillus. Eur J Cardiothorac Surg 2001;20(1):211-213.

4. Dacosta NA, Kinare SG. Association of lung carcinoma and tuberculosis. J Postgrad Med 1991;37(4):185-189.

5. Lande L, Peterson DD, Gogoi R, Daum G, Stampler K, Kwait R, et al. Association between pulmonary Mycobacterium avium complex infection and lung cancer. J Thorac Oncol 2012;7(9):1345-1351.

6. Lee PN, Forey BA, Coombs KJ. Systematic review with meta-analysis of the epidemiological evidence in the 1900s relating smoking to lung cancer. BMC Cancer 2012;12:385.

7. Winer-Muram HT, Jennings SG, Tarver RD, Aisen AM, Tann M, Conces DJ, Meyer CA. Volumetric growth rate of stage I lung cancer prior to treatment: serial CT scanning. Radiology 2002;223(3):798805 .

8. Wilson DO, Ryan A, Fuhrman C, Schuchert M, Shapiro S, Siegfried JM, Weissfeld J. Doubling times and CT screen-detected lung cancers in the Pittsburgh Lung Screening Study. Am J Respir Crit Care Med 2012;185(1):85-89.

9. Woodring JH, Fried AM. Significance of wall thickness in solitary cavities of the lung: a follow-up study. AJR 1983;140(3):473-474.

10. Woodring JH, Fried AM, Chuang VP. Solitary cavities of the lung: diagnostic implications of cavity wall thickness. AJR 1980;135(6): 1269-1271.

11. Madri JA, Carter D. Scar cancers of the lung: origin and significance. Hum Pathol 1984;15(7):625-631.

12. Jiva TM, Jacoby HM, Weymouth LA, Kaminski DA, Portmore AC. Mycobacterium xenopi: innocent bystander or emerging pathogen? Clin Infect Dis 1997;24(2):226-232. 